\title{
Féeries
}

Études sur le conte merveilleux, XVII $-\mathrm{XIX}{ }^{\mathrm{e}}$ siècle

10 | 2013

Conte et croyance

\section{Charles Perrault, Contes}

texte établi, présenté et annoté par Tony Gheeraert, Paris, Honoré

Champion, "Champion classiques », série « Littératures », 466 p., 2012

\section{Anne Defrance}

\section{(2) OpenEdition}

12 Journals

Édition électronique

URL : http://journals.openedition.org/feeries/875

DOI : $10.4000 /$ feeries.875

ISSN : 1957-7753

Éditeur

UGA Éditions/Université Grenoble Alpes

\section{Édition imprimée}

Date de publication : 20 septembre 2013

Pagination : 297-298

ISBN : 978-2-84310-253-0

ISSN : 1766-2842

\section{Référence électronique}

Anne Defrance, «Charles Perrault, Contes », Féeries [En ligne], 10 | 2013, mis en ligne le 20 mars 2015, consulté le 22 septembre 2020. URL : http://journals.openedition.org/feeries/875 ; DOI : https:// doi.org/10.4000/feeries.875 
Contes, Charles Perrault, texte établi, présenté et annoté par Tony Gheeraert, Paris, Honoré Champion, "Champion classiques", série "Littératures", ISBN 978-2-7453-2218-0, 466 p., 2012.

Les éditions Honoré Champion ont entrepris depuis quelques années de rééditer dans une collection de poche quelques ouvrages de leur "Bibliothèque des Génies et des Fées». Après les deux volumes des Contes des fées et Contes nouveaux de Madame d'Aulnoy réédités en 2008 par Nadine Jasmin (recueils phares qui avaient ensemble constitué en 2004 le premier volume de cette luxueuse anthologie), après Les Mille et un Jours de Pétis de La Croix par Christelle Bahier-Porte (2009-20II), ce sont à présent les contes de Perrault qui trouvent - ou retrouvent plutôt — ici, une autonomie. Cette édition reprend en effet intégralement, en la remaniant quelque peu, celle des contes de l'auteur vedette du volume 4 de la collection, volume intitulé Perrault, Fénelon, Mailly, Préchac, Choisy et anonymes. Contes Merveilleux (abrégé au dos de l'ouvrage en Perrault et autres conteurs), édité en 2005 par Tony Gheeraert, et qui avait fait l'objet d'une recension par Delphine Reguig-Naya dans le numéro 4 de Féeries (20075). La nouvelle édition affiche sous une étiquette très classique les textes du plus célèbre des auteurs de contes, puisqu'elle use du titre générique qui s'était imposé dans la majorité des éditions depuis le XviII ${ }^{\mathrm{e}}$ siècle. On trouvera donc à nouveau réunis et accompagnés du même apparat critique (même annotation des textes, eux-même publiés à l'identique), non seulement les contes en vers et les Histoires ou contes du temps passé, mais encore les intéressantes annexes proposées antérieurement dans la «Bibliothèque des Génies et des Fées». Il s'agit des Lettres sur Griselidis et Peau d'Âne (parues anonymement dans le recueil Moetjens de 1694), des Contes de ma mère l'oie (manuscrit de I695), de la version de «La Belle au bois dormant» publiée en I696 par le Mercure galant, et enfin de la «Peau d'Âne» en prose (version anonyme mais retenue pour l'édition Hetzel de I862 illustrée par Gustave Doré).

En couverture de la présente, on annonce une «édition augmentée de nouvelles notices ». En effet, la mise à jour effectuée ne concerne sensiblement qu'elles. Les maigres notices de l'édition antérieure, placées en fin de volume, venaient compléter une très copieuse introduction auxquelles elles renvoyaient. Ces notices présentaient en quelques lignes les sources des contes, indiquaient leurs affiliations aux contes-types de la classification Aarne et Thompson, et cela pouvait suffire parce que les contes avaient été

I5. Je renvoie à cette recension accessible en ligne sur :<http://feeries.revues.org/443>. 
analysés l'un après l'autre avec précision dans une section de l'introduction intitulée "Sources orales et sources écrites", qui opérait une répartition tripartite entre les "contes d'origine exclusivement orale", un conte dont on se demandait s'il était "d'origine uniquement livresque» («La Belle au bois dormant»), et enfin les "contes mixtes». La nouvelle édition de poche offre un découpage sensiblement différent : les notices, plus informatives, se trouvent ici augmentées du contenu de l'ancienne section évoquée précédemment, qui a donc naturellement disparu de l'introduction. Ce transfert propose donc une disposition sans doute plus efficace (et moins engagée - ou plus prudente) en ce qui concerne la classification des contes suivant leurs sources orales/sources écrites — ou leur nature de contes populaires/ contes littéraires. D'ailleurs une note de bas de page (p. 40) précise que ces deux couples d'opposition "ne se recouvr[e]nt pas entièrement». Le lecteur qui attend du neuf pourra se satisfaire de nouvelles analyses venues compléter et enrichir en fin de notice la matière recyclée telle quelle, si je ne m'abuse, pour la majorité des contes. Autres modifications visibles : à l'index des personnages que l'on trouve dans chaque volume de la «Bibliothèque des Génies et des Fées», Tony Gheeraert a préféré un «Index des principaux noms cités »; les résumés des contes ont également disparu. Ces deux sections étaient soumises aux principes éditoriaux de l'anthologie. Enfin, le commentaire du frontispice des Histoires ou contes du temps passé, assez inattendu dans la table des illustrations de l'édition antérieure, a été lui aussi déplacé, enrichi et mis à l'honneur dans les notices.

Je formulerai un seul regret : que la bibliographie publiée en 2008 n'ait pas été réactualisée (le dernier ouvrage référencé datant de 2004), alors que pendant les huit années séparant cette référence de l'édition dont il est ici question, des travaux novateurs ont paru qui ont marqué les études perraldiennes, voire les théories du conte.

Quoi qu'il en soit, il faut se réjouir que le prix modéré de cette collection de poche rende enfin très accessible l'excellente édition des contes de Perrault produite par Tony Gheeraert. Sa précédente, toujours vendue, n'en paraît que davantage destinée aux bibliothèques, tout comme les autres volumes de la collection, qui eux ne bénéficient pas d'une semblable réédition en format poche. Si cette dernière détrône sa grande sœur, celle-ci, toujours disponible en librairie, reste toutefois indispensable aux chercheurs pour les autres auteurs qu'elle présente et dont les contes sont sans doute moins connus que ceux de l'académicien (Fénelon, Préchac, Mailly...) mais sont commentés de manière tout aussi pertinente. 